\title{
Documentos
}

\section{La filosofía, los filósofos y el Instituto de Investigaciones Filosóficas de la UNAM. $70^{\circ}$ Aniversario}

\author{
LAURA BENÍTEZ \\ Instituto de Investigaciones Filosóficas \\ Universidad Nacional Autónoma de México \\ grobet@servidor.unam.mx
}

Resumen: En este documento se recogen los momentos considerados más importantes en el desarrollo histórico del Instituto de Investigaciones Filosóficas de la UNAM. Este recorrido se ha dividido en tres etapas: los orígenes, la consolidación institucional y la expansión, lo cual permite adentrarse en los propósitos, las líneas directrices, los avances y las metas logradas, y poner especial atención en los fundadores de esta institución así como en el clima intelectual en que surgió. Se ha procurado seguir las propuestas de los diversos directores y el impulso que dieron al desarrollo del Instituto con importantes programas académicos, abriendo nuevas rutas a la investigación, la docencia, los programas editoriales y el incesante crecimiento de la biblioteca "Eduardo García Máynez". En suma, se ha querido plasmar la importancia de una comunidad filosófica activa y vigorosa cuya labor es reconocida por otras comunidades filosóficas dentro y fuera de nuestro país.

Palabras clave: desarrollo institucional, comunidad filosófica, investigación filosófica, docencia en filosofía

\begin{abstract}
In this paper I take in account the most relevant aspects of the historical development of the Instituto de Investigaciones Filosóficas at the UNAM. I divided this presentation in three stages: the origins, the institutional reinforcement and the expansion. Such division allows me to understand the purposes, the directions, the steps forward and the achievements of this institution, focused in the founders and in the intellectual climate in which it comes out. In the same manner I intend to follow the proposals of the different directors and the impulse they gave to the development of the Institute with very important academicals programs, like opening new areas for philosophical research, creating new programs for teaching philosophy, as well as the consolidation of very important editorial programs and the unceasing growth of the library "Eduardo García Máynez". In brief, I try to capture the importance of a vigorous and active philosophical community which work is recognized in other philosophical communities in and out of our country.

Key words: institutional development, philosophical community, philosophical research, philosophical teaching
\end{abstract}




\section{Introducción}

Como toda realidad histórica humana, las instituciones, aun cuando aparentan tener un derrotero propio y definido, una especie de destino manifiesto, no son en el fondo sino la suma de los sueños, los esfuerzos y la creatividad de todos los que de ella forman parte. Sin embargo, como en toda empresa humana, se requiere dirección, objetivos, visión de largo plazo y un entorno que permita llevar a cabo los propósitos comunes.

El Instituto de Investigaciones Filosóficas ha sido a lo largo de estos setenta años de existencia una institución modélica en el impulso y desarrollo de distintas áreas y disciplinas filosóficas, en la formación de profesionales de la filosofía, en la interacción con grupos filosóficos y filósofos del mundo occidental, y en la proyección y difusión de la filosofía a través de sus numerosas publicaciones.

Pero lo que el Instituto es hoy, a setenta años de su creación, no es explicable sino como el resultado de un desarrollo histórico que ha conocido, a mi ver, tres importantes etapas. La primera es, desde luego, la de sus orígenes; para muchos, verdaderamente "heroicos". La segunda nos remite a su consolidación institucional, y la tercera, que podemos entender como su etapa de expansión, explica el sentido de nuestro hacer actual.

En lo que sigue mencionaré cada una de ellas en su especificidad, pero sin perder de vista que no sólo en sus objetivos, sino en su estructura básica, esta institución ha reafirmado su propia identidad y vocación filosófica.

\section{Primera etapa: los orígenes}

En su "Breve historia del Centro de Estudios Filosóficos", el doctor Eduardo García Máynez refiere que:

En el mes de agosto de 1940, poco después de haber sido electo Director del plantel de Mascarones, decidí fundar un Centro de Estudios al que podrían pertenecer los profesores de materias filosóficas que estuvieran interesados en reunirse periódicamente con sus colegas para leer y discutir, en sesiones de mesa redonda, trabajos sobre temas de filosofía. ${ }^{1}$

Fuera de contexto, este primer paso se antoja modesto; sin embargo, es el producto de una preocupación que aún hoy sigue viva entre quienes

${ }^{1}$ E. García Máynez, "Breve historia del Centro de Estudios Filosóficos", p. 240. 
cultivamos la filosofía. En efecto, formar una comunidad filosófica tiene como premisa principal el fortalecimiento del diálogo entre sus miembros. ${ }^{2}$ La preocupación no era, pues, fundar una simple asociación, sino romper el aislamiento entre los profesores, propiciar el conocimiento de las propuestas del otro con un importante ingrediente crítico. La preocupación del fundador se remitía entonces, en suma, a la preocupación por la carencia de una auténtica comunidad filosófica, la cual, se pensó, debería ser realmente incluyente, ya que se convocaba tanto a los profesores de Facultad como a los de la Escuela Nacional Preparatoria, y se amplió a "cualquier cultivador de la filosofía, fuese o no catedrático de la Universidad Nacional de México". ${ }^{3}$

Sin embargo, el Centro de Estudios Filosóficos de la Facultad de Filosofía y Letras, enriquecido con la presencia de los transterrados españoles, le sugirió a García Máynez la posibilidad de ampliar los horizontes de esa pequeña pero activa comunidad, con "una serie de empresas editoriales". ${ }^{4}$ La primera de ellas fue la publicación del Boletín Bibliográfico, que en sus trece números contó con más de 130 reseñas, las cuales, desde luego, cumplían con la función de poner al día en temas filosóficos a sus lectores; pero, más allá de esto, permitió dar a conocer los propósitos y las actividades del Centro. Así, en el primer Boletín, que apareció en octubre de 1940, un mes después de creado el Centro, se hicieron patentes las preocupaciones de la naciente comunidad en lo que puede considerarse como una declaración de principios:

El presente Boletín es la primera publicación del Centro de Estudios Filosóficos de la Facultad de Filosofía y Letras. La finalidad esencial del Centro consiste, como su nombre lo indica, en cultivar y fomentar el estudio de las disciplinas filosóficas, dentro y fuera de la universidad de México. Para el logro de este propósito, organizará periódicamente pláticas, cursos y conferencias y publicará los trabajos de sus socios, las actas de las discusiones y una serie de textos clásicos de filosofía. ${ }^{5}$

${ }^{2}$ Recientemente, Guillermo Hurtado ha expresado que: "Una comunidad filosófica no debe confundirse con un conjunto de filósofos que viven en un mismo país, región o que trabajan sobre temas afines o con una metodología similar o que son miembros de una misma asociación o de una misma facultad [.. . ]. Una comunidad filosófica verdadera es un conjunto de filósofos que, además de compartir algunos o todos los elementos anteriores, entablan un diálogo o varios de ellos" (G. Hurtado, El búho y la serpiente. Ensayos sobre filosofía en México en el siglo XX, pp. 35-36).

${ }^{3}$ García Máynez, ibid., p. 240.

${ }^{4}$ Ibid.

${ }^{5}$ Ibid. 
Los inicios del proyecto editorial del Centro revelan algunas cuestiones de fondo. En efecto, mientras que a "las palabras (habladas) se las lleva el viento", el diálogo escrito compromete a los autores con sus ideas, con la formulación precisa de su pensamiento. Las memorias de las "discusiones", a la par que hacen patente el compromiso teórico de los filósofos con diversas escuelas, permiten la consolidación del quehacer filosófico profesional.

Este reforzamiento del quehacer filosófico no quedaría completo sin la publicación de los trabajos producidos por los miembros y discutidos en el Centro; sin embargo, como no contaba con una revista propia, muchos de ellos fueron publicados en la revista Filosofía y Letras, órgano de la Facultad, que el propio García Máynez había echado a andar desde fines del año 1940 y de la cual dirigió 43 números de los 69 que comprende. $\mathrm{Al}$ respecto comenta:

Si me he detenido a hablar de Filosofía y Letras, pese a que no era una publicación del Centro, sino órgano de la Facultad, ello se debe a que, como lo revela la lista de sus colaboradores, éstos fueron, en buena parte, las mismas personas que dieron vida a nuestra sociedad, e hicieron posible especialmente entre 1940 y 1945, realizar las tareas iniciadas, cuando tuve el honor de dirigir la escuela de Mascarones. ${ }^{6}$

Pero el aliento para las empresas editoriales de García Máynez no sólo se materializó en el Boletín Bibliográfico y en la revista Filosofía y Letras, sino que como subdirector de la Facultad de Filosofía en el año 1941 dio inicio tanto a la serie Monografías Filosóficas como a la de Textos Clásicos de Filosofía. Lo importante en este caso es que cinco monografías aparecieron con el nombre del Centro, en tanto que la colección de Textos Clásicos fue preparada y elaborada por los miembros del Centro. Así lo refiere García Máynez:

Los textos publicados entre 1941 y 1944 fueron:

Kant, Filosofía de la historia. Prólogo y traducción de Eugenio Ímaz, 1941. Giambattista Vico, Principios de una ciencia nueva en torno de la naturaleza común de las naciones. 2 tomos. Prólogo y traducción de José Carner, 1941.

Adam Smith, Teoría de los sentimientos morales. Introducción de Eduardo Nicol. Traducción de Edmundo O'Gorman, 1942.

Edmundo Husserl, Meditaciones cartesianas. Prólogo y traducción de José Gaos, 1942.

${ }^{6}$ Ibid., p. 241.

Diánoia, vol. LV, no. 64 (mayo 2010). 
Los Presocráticos. 2 volúmenes. Traducción y notas de Juan David García Bacca, $1944 .^{7}$

El listado es revelador en cuanto a la circunstancia histórica. El propio García Máynez reconoce el papel fundamental del "grupo de maestros españoles" (José Gaos, Eduardo Nicol, Luis Recaséns Siches, Joaquín Xirau, Eugenio Ímaz y José Gallegos Rocafull) tanto en las empresas editoriales como en "las actividades docentes y en el cultivo y difusión de las ideas filosóficas". ${ }^{8}$ En efecto, la llegada de los profesores españoles entre 1937 y 1940, debido a la guerra civil en aquel país, fue la circunstancia propicia que permitió a García Máynez llevar a cabo diversos propósitos académicos y que estimuló, sin duda alguna, otros con respecto al Centro de Investigaciones Filosóficas. No obstante, sería injusto olvidar el otro lado, ya que en ese momento sobresalen intelectuales mexicanos como Antonio Caso, Ezequiel A. Chávez, Alfonso Reyes, Samuel Ramos y José Vasconcelos. De aquí que García Máynez califique de "feliz" la circunstancia histórica que permitió esta conjunción, pero es aún más feliz para nosotros, herederos de una muy importante generación de mexicanos, pues: "García Máynez pertenece a esa generación de mexicanos ilustres [...] que fundaron las instituciones ilustradas y progresistas del México posrevolucionario".9

Los "tiempos heroicos"10 de la fundación del Centro dieron paso a nuevas e importantes circunstancias que permitieron otros desarrollos académicos. En efecto, en diciembre de 1944 fue expedida la Ley Orgánica de la Universidad por el presidente Manuel Ávila Camacho, y en 1945 el Centro de Estudios Filosóficos fue elevado a la categoría de instituto autónomo, cuyo director fue el propio García Máynez. La autonomía de los institutos respecto de las facultades no fue en un principio bien recibida por todos los universitarios, pero los más progresistas comprendieron que la creación de nuevo conocimiento se ve limitada en las aulas a los niveles de formación de los estudiantes. Por tal razón considero que éste fue un momento clave en el desarrollo institucional de los futuros institutos de investigación que surgieron, en un inicio, a partir de las facultades de Humanidades y de Ciencias. Por ello puede decirse que la perspectiva de García Máynez era privi-

${ }^{7}$ Ibid.

${ }^{8}$ Ibid.

${ }^{9}$ G. Hurtado, op. cit., p. 180.

${ }^{10}$ En su artículo "El Instituto de Investigaciones Filosóficas", Fernando Salmerón consigna que: "Las páginas en que García Máynez ha evocado esos recuerdos suenan, a la distancia de los años, como un relato de tiempos heroicos..." (p. 3). 
legiada, pues encarnaba las preocupaciones de la Escuela de Altos Estudios que él conocía ampliamente. Si la idea era formar profesionales de la filosofía, investigadores competentes en sus distintas disciplinas, lo primero era contar con un programa de becas que permitiera a los estudiantes y profesores capaces adquirir una formación de alto nivel. Por otra parte, siendo la investigación tarea prioritaria de un instituto, el otro objetivo inmediato fue la adquisición de libros y revistas. Así, desde su planteamiento original, el Instituto de Investigaciones Filosóficas nació con el doble derrotero de formar profesionales estudiosos de la filosofía y crear una biblioteca especializada en esos temas. A la consolidación de jure del Instituto hubo de añadirse la de facto. En efecto, a partir de 1945, el Centro contó con un presupuesto modesto pero propio que, junto con otros subsidios, permitieron que entre 1945 y 1947 se pudieran otorgar ocho becas y se publicara una colección de cinco títulos originales de Nicol, Fuentes Mares, Zea, Larroyo y el propio García Máynez.

Para 1948, el Instituto contaba ya con un reglamento de trabajo que evidenciaba sus objetivos, los cuales sin duda han marcado su rumbo y desarrollo. Desde el primer artículo se advierte cómo se recogen las tareas sustantivas de la Universidad: docencia, investigación y difusión de la cultura.

Realizar dentro de la Universidad, y fomentar en todo el país, los trabajos de investigación en materias filosóficas, así como dar a conocer tales trabajos por medio de mesas redondas, conferencias, publicaciones, seminarios o cursos especiales.

Asimismo, es claro que las relaciones de colaboración e intercambio entre pares nacionales y extranjeros urgían a la elaboración de un directorio filosófico para no permanecer como una comunidad aislada. Desde luego, se reiteró la necesidad de formar una biblioteca y una hemeroteca especializadas en filosofía, pero lo que más llama la atención es que esta naciente comunidad se vio a sí misma en perspectiva histórica y por ello consideró fundamental el estudio histórico de la filosofía mexicana, pues al desconocer los antecedentes en el pasado se corre el riesgo de perder el rumbo hacia el futuro. En 1947 se contó en el presupuesto con el rubro de becas, lo que permitió que de allí a 1953 el Centro pudiera otorgar diecinueve becas de estudio, puesto que no había dinero para tener investigadores de planta. Al mismo tiempo, la propia Universidad se encargó de la impresión de las publicaciones del Centro, que entre 1947 y 1951 se dio a la tarea de realizar diversos 
homenajes: a Antonio Caso, a Cervantes, a Goethe, así como la conmemoración del cuarto centenario de la fundación de la Real y Pontificia Universidad de México. ${ }^{11}$

El año 1954 marca un cambio importante no sólo por el traslado de la Universidad a la Ciudad Universitaria, ${ }^{12}$ sino porque ello coincide con la consolidación de la institucionalización de la investigación. En la Torre de Humanidades, el Centro contaba con un área propia para realizar la tares de investigación filosófica. ${ }^{13}$ En ese mismo año se hicieron los primeros nombramientos de investigador y se creó Diánoia, anuario del Centro cuyo objetivo para el fundador era "ser un órgano especializado de filosofía en plan científico y con carácter internacional". ${ }^{14}$ También dio inicio la Colección de Diánoia, que dio oportunidad a los investigadores del Centro para plasmar sus trabajos. En el año 1959 se inició la colección Filosofía Contemporánea, destinada a difundir el pensamiento filosófico contemporáneo a través de la traducción de textos de autores connotados. A estas colecciones se añadió, también en 1959, la colección Cuadernos del Centro de Estudios Filosóficos, que se dedicó a la traducción de textos filosóficos breves. El objetivo de ambas colecciones era "difundir varias de las mejores obras del pensamiento filosófico mundial". ${ }^{15}$

El Centro funcionó bajo la dirección de García Máynez hasta el año 1965, bajo la premisa de respetar la libertad de investigación y poniendo el acento en el quehacer individual, ya que en ese momento no se concebía que en la filosofía pudiera existir una labor de equipo.

${ }^{11}$ García Máynez menciona que entre los textos de esta celebración están: " $L a$ idea del descubrimiento de América de Edmundo O'Gorman; El pensamiento mexicano en los siglos XVI y XVII del padre José María Gallegos Rocafull y Coatlicue. Estética del arte indígena antiguo, de Justino Fernández" (García Máynez, op. cit., p. 245).

${ }^{12}$ Fernando Salmerón refiere: "A partir de 1954 con el paso a la Ciudad Universitaria, comienza el período de 'institucionalización', el nombramiento de los primeros investigadores de carácter permanente, la ampliación de la biblioteca y la creación de las series de publicaciones que no se han interrumpido hasta la fecha" ("El Instituto de Investigaciones Filosóficas", p. 3).

${ }^{13}$ Para García Máynez: "Los beneficios han sido grandes para todos, pero especialmente, para quienes - acatando un imperativo vocacional- hemos resuelto consagrar nuestras vidas a las tareas de investigación [...]" (García Máynez, op. cit., p. 246).

${ }^{14}$ Ibid.

${ }^{15}$ Ibid., p. 248.

Diánoia, vol. LV, no. 64 (mayo 2010). 


\section{Segunda etapa: la consolidación institucional}

En el año 1965 Fernando Salmerón fue designado director del Centro, y en diciembre de 1967 este organismo recibió su nombre definitivo: Instituto de Investigaciones Filosóficas. La consolidación era evidente. De 1954 a 1965, el Instituto contaba con un presupuesto de casi novecientos mil pesos, la biblioteca contaba con ocho mil volúmenes y recibía 43 revistas. En el cuarto piso de la Torre de Humanidades laboraban nueve investigadores de planta, pero no había becarios y el intercambio entre investigadores era escaso. A lo largo de los doce años de dirección de Fernando Salmerón se fortalecieron tanto el programa de becarios como la búsqueda de rigor en las tareas de investigación, lo cual permitió el acercamiento entre los investigadores así como, a la larga, la formación de grupos de trabajo. Al final de su gestión en 1978, el presupuesto era mayor a los trece millones y medio de pesos, había veintiún investigadores, cinco becarios en el extranjero realizando estudios de posgrado y seis en el Instituto formándose para la investigación. La biblioteca poseía ya quince mil volúmenes y recibía 110 revistas filosóficas por suscripción y cuarenta por canje. Las áreas de investigación fueron definidas y reforzadas por los programas de becarios y de incorporación de investigadores extranjeros. Para 1975, Salmerón reportaba cuatro áreas sustantivas: epistemología y filosofía del lenguaje, historia y filosofía de la ciencia, ética y filosofía del derecho y estética e historia de la filosofía. ${ }^{16}$ Con una clara visión de futuro Salmerón expresó:

Estas áreas han de ser el espacio permanente para la discusión no improvisada, para el surgimiento natural de investigaciones realizadas por más de un miembro del instituto, para el clima intelectual que los becarios recién graduados deben hallar en el momento de su ingreso, y aún para organizar el gobierno del instituto, por la participación de representantes en el Consejo Interno. ${ }^{17}$

Salmerón percibió asimismo que los planes presupuestales deberían contemplar no sólo la incorporación de investigadores, sino los proyectos de investigación, haciendo un diagnóstico de las áreas. Ello permitiría definir los objetivos de la investigación, dar continuidad a los proyectos y reforzar la comunidad de los investigadores. A la vez visualizó la importancia de que los investigadores participaran en la docencia, no sólo a título individual, sino con cursos especiales de posgrado; si

${ }^{16}$ Cfr. Salmerón, op. cit., p. 10.

${ }^{17}$ Ibid. 
bien dichos cursos no se llevaron a cabo en ese momento, constituyen un importante antecedente de nuestra actual corresponsabilidad en los programas de posgrado en filosofía y en filosofía de la ciencia.

Salmerón veía con claridad cómo:

De ponerse en práctica proyectos de este tipo, el Instituto puede representar un papel destacado y, desde luego, distinto al de cualquier otro instituto dentro de la Universidad, en la medida en que puede servir de puente natural entre varias disciplinas $[\ldots]^{18}$

La fuerte liga entre la filosofía y la investigación científica, tanto en ciencias exactas y naturales como en ciencias sociales, que culminaría con la formación de investigadores de alto nivel en las diferentes disciplinas, se ve como una realidad cumplida, toda vez que el CONACYT otorgó en 2008 a la Maestría en Filosofía de la Ciencia la calificación de "Competencia Internacional"; asimismo, el Doctorado en Filosofía de la Ciencia, al igual que la Maestría y el Doctorado en Filosofía, se encuentran incluidos hoy en el Programa Nacional de Posgrados de Calidad. En todos los casos el Instituto es, como entidad participante, fundamental en el desarrollo de las actividades de estos posgrados, así por el número importante de tutores comprometidos con estos programas, como por el apoyo logístico y de infraestructura para llevar a cabo las actividades requeridas.

Desde 1966, las reuniones académicas de los investigadores del Instituto permitieron desarrollar un clima de trabajo continuado y de colaboración intelectual que ha permitido que se desarrollen proyectos no sólo en colaboración con otras dependencias de la UNAM, sino con otras universidades nacionales y extranjeras. Entre 1966 y 1977 se registraron tres importantes reuniones académicas y un seminario especializado que constituyó la punta de lanza del área de filosofía de la ciencia, auspiciada por Mario Bunge, Mario Otero y Ulises Moulines en 1977.

De 1967 a 1977 la lista de investigadores visitantes no sólo es muy amplia (46 visitantes), sino que en el Instituto se dieron cita los filósofos contemporáneos de mayor renombre de las más importantes universidades de América Latina, Estados Unidos y Europa; esto coadyuvó a la participación de los investigadores del Instituto en reuniones académicas, impartición de cursos y estancias de investigación en importantes centros de filosofía fuera del país. Cabe señalar que estas actividades no sólo se han mantenido — como ocurrió en el período referido- a título

$$
{ }^{18} \text { Ibid., p. } 10 .
$$


personal, sino que han recibido un gran apoyo institucional; gracias a ello se han fortalecido y ampliado enormemente a través de los proyectos de investigación y del apoyo e interés de los sucesivos directores.

Las publicaciones del Instituto no sólo se consolidaron entre los años 1966 y 1978, sino que se incrementaron notablemente. Pero ¿cuál es en verdad su significado? Al respecto, Fernando Salmerón comenta en su informe de doce años como director (1966-1978):

La historia del Instituto bien podría contarse a partir de sus empresas editoriales, lo mismo por las publicaciones que son el resultado de las investigaciones de sus miembros, que por las ediciones de libros extranjeros y autores clásicos, necesarias para la enseñanza de la filosofía y el conocimiento de sus problemas. ${ }^{19}$

Ya desde 1955 se había iniciado la Colección de Diánoia, destinada a recoger los trabajos de los investigadores, y a finales de los años cincuenta se iniciaron las colecciones Filosofía Contemporánea y Cuadernos del Centro. En la primera se publicaron, durante el período de referencia, cinco importantes títulos, en tanto que en Cuadernos se publicaron diecisiete títulos , en su mayoría traducciones de textos clásicos y contemporáneos. Por último, la colección Filosofía Contemporánea se dividió a partir de 1966 en cuatro series: Monografías, Textos Introductorios, Textos Fundamentales y Antologías, y en el periodo referido se publicaron dieciocho títulos. ${ }^{20}$

Si por algo se ha señalado el Instituto en su período de institucionalización y consolidación crecientes es por la importancia de sus publicaciones periódicas. En efecto, desde 1955 hasta 2009, Diánoia no ha dejado de aparecer, e incluso aumentó la frecuencia de su aparición de anual a bianual desde hace tres años. Por otra parte, ha de señalarse que la creación de la revista Crítica nos acerca con particular precisión a la realidad histórica de nuestro Instituto. Las palabras de Salmerón son ilustrativas al respecto:

Se buscaba una publicación de mayor frecuencia en su periodicidad, más ágil que Diánoia para la discusión filosófica y menos interesada en la his-

${ }^{19}$ Ibid., p. 14.

${ }^{20}$ Cabe señalar que la importancia de lo publicado queda cabalmente de manifiesto en el minucioso informe de Fernando Salmerón, que destaca los títulos de las obras así como de los autores nacionales y extranjeros que participaron en estas empresas editoriales. 
toria de la filosofía, en el pensamiento latinoamericano tradicional y en los sistemas especulativos. ${ }^{21}$

Las preocupaciones iban en la línea de una filosofía científica, muy claramente analítica, interesada en los problemas contemporáneos de la filosofía, particularmente los de la lógica, la filosofía del lenguaje y la filosofía de la mente. Desde 1967, cuando apareció el primer número, se ha seguido publicando hasta la fecha con una periodicidad de tres veces al año. Sin embargo, como todo instrumento filosófico, a través de sus distintos comités editoriales y colaboradores Crítica fue afinando sus criterios, en especial en cuanto a sus contenidos. Ya en 1978 Salmerón expresaba que:

Ciertamente, la revista había sostenido un alto nivel teórico, pero ni había realizado la tarea didáctica a que estaba obligada en nuestros países, ni había ofrecido el análisis crítico de la producción intelectual que entre nosotros ocupa el verdadero lugar de la actividad filosófica. ${ }^{22}$

A la vez, Salmerón encontraba que en Crítica no habían tenido cabida ni la filosofía de la historia, ni la filosofía política, ni la filosofía de la educación, ni tampoco los problemas de filosofía moral. Desde luego que estas preocupaciones han llevado a la apertura de Crítica a estas áreas filosóficas - y a otras como la filosofía del derecho- conservando siempre un alto nivel de exigencia teórica.

Además de las publicaciones periódicas se deben señalar las series y colecciones por su creciente importancia: Cuadernos de Crítica, que a la fecha cuenta con 53 números y pone al alcance de los estudiantes textos breves de filosofía contemporánea. Por otra parte, la colección Estudios Monográficos, concebida especialmente para publicar el trabajo de los becarios, cuenta con nueve títulos.

Además de las citadas, las series concebidas para publicar el trabajo de los investigadores se han diversificado en vista de las múltiples áreas filosóficas que se cultivan actualmente en el Instituto, así como de los diversos proyectos que han generado una buena cantidad de publicaciones. Podemos, pues, mencionar: la colección Cuadernos, que cuenta a la fecha con 66 títulos; la de Estudios Clásicos, que incluye veintitrés textos; y la de Filosofía Contemporánea, en la que se presentan tanto traducciones de textos filosóficos de autores contemporáneos — realizadas en su mayoría por investigadores del Instituto-, como

${ }^{21}$ Ibid., p. 16.

${ }^{22}$ Ibid., p. 17.

Diánoia, vol. LV, no. 64 (mayo 2010). 
estudios propios de los investigadores, y que se compone, a la fecha, de 77 títulos. Además, las colecciones de Historia de la Filosofía y Filosofía de la Ciencia cuentan con seis títulos; la de La Filosofía y sus Problemas, diseñada específicamente para proyectos de investigación, se compone de catorce títulos; las de Historia de la Filosofía y de Homenajes cuentan con seis títulos, y la de Publicaciones de Diánoia, con veinte títulos. A éstas hay que agregar otras 35 obras que corresponden a Symposia, Textos Clásicos, boletines y otros títulos.

Mención especial merece la Nueva Biblioteca Mexicana, en la que se han publicado dieciocho títulos, así como las coediciones, que suman diecinueve títulos más. Finalmente, la Bibliografía filosófica mexicana, además de reunir veinte títulos impresos, cuenta en la actualidad con un disco compacto que recoge de manera sistemática la bibliografía filosófica de los últimos cincuenta años y se pretende tener a futuro, también en medios electrónicos, la bibliografía filosófica mexicana de todo el siglo Xx. En suma, de 1940 a 2007 el Instituto ha llegado a publicar 576 títulos entre libros y publicaciones periódicas. ${ }^{23}$

Este continuo desarrollo en la labor editorial habla no sólo de la consolidación del Instituto, sino también de su expansión; en efecto, si bien a la generación del doctor Salmerón le tocó "consolidar la vida académica" y "mantener la continuidad de los programas" editoriales, de becarios, de visitantes y de estancias de investigación, las siguientes generaciones han buscado la expansión del Instituto en todos los niveles, desde los nuevos espacios físicos, siempre en reaprovechamiento y remodelación, hasta nuevos y variados programas y diversificación de las fuentes de financiamiento para proyectos de investigación y nuevos modelos y plazas de enseñanza.

\section{Tercera etapa: la expansión}

A partir del año 1978 la dirección del Instituto ha recaído en sucesivas generaciones de jóvenes formados en su mayoría en los programas de posgrado de universidades anglosajonas de primer nivel (Oxford, Stanford, etc.). Así, en 1978 asumió la dirección el maestro Hugo Margáin, a cuya muerte prematura lo sucedió el doctor Enrique Villanueva, quien cubrió el periodo 1978-1985. Para entonces, el Instituto contaba con veintidós investigadores y el trabajo filosófico se había divido en cinco áreas: lógica filosófica y filosofía del lenguaje, metafísica y filosofía

${ }^{23}$ Para mayor ampliación de estos datos véase el Catálogo histórico de publicaciones del Instituto de Investigaciones Filosóficas. 1940-2007.

Diánoia, vol. LV, no. 64 (mayo 2010). 
de la mente, epistemología y filosofía de la ciencia, filosofía práctica e historia de la filosofía. Además del seminario de investigadores, se reforzaron dos seminarios de área y se reportaba que todos los investigadores desarrollaban labores docentes en la UNAM y algunos en la Universidad Autónoma Metropolitana, Unidad Iztapalapa. Asimismo, se consolidaron las reuniones académicas organizadas por el Instituto, como el Simposio Internacional de Filosofía, que en 2008 alcanzó su vigésima cuarta edición. Durante todo el año, y en particular para los diversos eventos académicos y cátedras extraordinarias, fueron invitados en el período que nos ocupa al menos veinticinco profesores extranjeros reconocidos internacionalmente por su importante producción filosófica.

Para el año 1984 el Instituto contaba con cuatro publicaciones periódicas: Diánoia, Crítica, Bibliografía filosófica mexicana y el boletín Filosóficas. Por otra parte, se reportaban doce colecciones de textos. ${ }^{24}$ Para ese entonces, la consolidación del programa de becas era una realidad actuante a través de la Dirección General de Asuntos del Personal Académico. En el período de referencia, al menos diez becarios fueron enviados a formarse en universidades británicas y de Norteamérica.

La biblioteca contaba ya con 15343 volúmenes y trescientos títulos de revistas especializadas. Finalmente, aun cuando entre los años 1983 y 1984 llegaron al instituto las primeras computadoras, el organigrama daba cuenta de que aún no habíamos entrado de lleno en la era computarizada pues en él no se registraba un departamento de cómputo, algo que se desarrollaría plenamente a finales de la década de 1980 y que fue ampliamente estimulado por los proyectos de investigación.

Entre los años 1985 y 1994, el doctor León Olivé se hizo cargo de la dirección del Instituto; fue éste, sin duda, un periodo de franca expansión en vista de que a los objetivos originales de investigación filosófica original, formación en filosofía, discusión filosófica entre especialistas y difusión del pensamiento filosófico, se añadieron las metas de incidir en la vida cultural de la nación, así como formar y actualizar a los profesores de filosofía. Además, se ampliaron de cinco a doce las líneas de investigación en el Instituto, añadiendo la filosofía de la historia, la filosofía política, la ética y la filosofía de la educación, y separando la filosofía de las ciencias - las cuales se dividieron en formales, naturales y sociales- de la epistemología, y la filosofía de la mente

${ }^{24}$ A las colecciones reportadas por el doctor Fernando Salmerón se añadieron nuevas series, como Simposios, Investigadores e Historia de la Lógica. Para mayor información sobre este particular, véase el folleto Instituto de Investigaciones Filosóficas elaborado por el propio Instituto en 1984.

Diánoia, vol. LV, no. 64 (mayo 2010). 
de la metafísica. ${ }^{25}$ La docencia, esto es, los cursos impartidos por los investigadores, abarcaba seis facultades y escuelas de la UNAM, siete universidades nacionales y siete universidades extranjeras; se consignó un total de sesenta cursos impartidos en el año 1990, y el Instituto contaba con 36 investigadores. En cuanto a la formación de investigadores, se consigna en un folleto de 1992:

Un número importante de investigadores del Instituto ha realizado posgrados en universidades extranjeras, muchos de ellos dentro del plan de formación de investigadores. El Instituto cuenta con egresados de las universidades de Indiana, Bloomington (E.U.), Stanford, California (E.U.), Minnesota (E.U.) y de las universidades de Oxford, Londres y Cambridge (Inglaterra) así como de la universidad de Constanza (Alemania). ${ }^{26}$

Para el año 1990 se reportaban veintiún becarios en proceso de formación y veintiocho tesis dirigidas por investigadores entre 1988 y 1990. Una aportación fundamental del Instituto a la vida académica de nuestra Universidad fue, sin duda, el acercamiento a la Facultad de Filosofía y Letras en el diseño de la maestría y el doctorado en Filosofía de la Ciencia.

La producción de los investigadores se elevó notablemente. Se reportaba una producción promedio de seis libros al año y el catálogo de publicaciones del Instituto contaba ya con doscientos títulos. ${ }^{27} \mathrm{~A}$ las publicaciones periódicas —Diánoia, Crítica y la Bibliografía filosófica mexicana - se añadieron las publicaciones de la biblioteca Actualidades filosóficas y el Catálogo de publicaciones periódicas, y del Departamento de Publicaciones, La galera. En cuanto a la publicación de libros, además de mantener las colecciones previas, el Instituto participó en el proyecto internacional para la edición de la Enciclopedia Iberoamericana de Filosofía, que no sólo habla de la madurez del quehacer filosófico en España y América Latina, sino de la fuerte interacción entre sus comunidades de especialistas, así como de la proyección y el nivel alcanzado por el Instituto.

Al desarrollo y expansión de las actividades investigativas, de docencia y difusión coadyuvaron de manera notable los programas de la Dirección General de Asuntos del Personal Académico; en particular, el

${ }^{25}$ Para este particular, véase el folleto Instituto de Investigaciones Filosóficas, elaborado por la Coordinación de Humanidades, p. 4.

${ }^{26}$ Ibid., p. 6.

${ }^{27}$ Ibid., p. 12.

Diánoia, vol. LV, no. 64 (mayo 2010). 
programa de proyectos de investigación dio especial impulso a la producción en la investigación, consolidó los equipos de trabajo, impulsó la carrera académica de los integrantes de los proyectos y permitió un intercambio académico sin precedentes. Por ello no es de extrañar que, al finalizar su primer período como director, el doctor León Olivé haya reportado siete proyectos colectivos de investigación y 36 proyectos individuales, veintidós libros publicados, veintiuna actividades académicas organizadas por el Instituto, 35 reuniones académicas (congresos, simposios, coloquios, etc.) a las que los investigadores asistieron y en las que se contó con la presencia de 35 invitados extranjeros. El resultado de esta intensa actividad se concretó en veintidós libros publicados en ese período (1988-1990).

Por otra parte, para esa fecha, la biblioteca del Instituto contaba ya con un acervo de 23000 libros y trescientos títulos de revistas especializadas; además, se había creado el Fondo Reservado de la biblioteca "García Máynez", y ya se contaba con el equipo de cómputo necesario para hacer consultas en LIBRUNAM.

Finalmente, es importante señalar que todos estos logros estuvieron enmarcados en el cambio de ubicación física del Instituto, entre 19861987, al nuevo edificio; esto permitió contar con los espacios idóneos para la realización de las labores de investigación. Se formó el Departamento de Cómputo y se tuvo el espacio adecuado para la biblioteca y su futuro desarrollo, y los investigadores contaron con nuevo equipamiento en los cubículos de investigación.

En 1993, la doctora Olga Elizabeth Hansberg ocupó la dirección del Instituto, cargo que desempeñó hasta el año 2000, cuando fue nombrada coordinadora de Humanidades. Sus principales logros fueron el fortalecimiento de la planta académica; el haber puesto en marcha los programas de maestría y doctorado en filosofía y en filosofía de la ciencia; la reinauguración de la Cátedra José Gaos, y el haber dado inicio al programa de estancias posdoctorales, que ha resultado muy beneficioso para nuestra labor de investigación.

La expansión académica del Instituto siguió adelante, por lo que hubo necesidad de aumentar y mejorar sus instalaciones. El creciente acervo de la biblioteca obligó a su ampliación; el Departamento de Cómputo contó con un laboratorio y un número creciente de máquinas para los usuarios. Además, al multiplicarse las actividades docentes hubo necesidad de contar con nuevos espacios para realizarlas, así como con nuevos cubículos tanto para los investigadores en estancia posdoctoral como para los que se reincorporaron después de realizar posgrados en universidades del extranjero. Del mismo modo, el creciente programa 
de estudiantes asociados al Instituto incidió en la necesidad de mayor número de espacios.

La doctora Paulette Dieterlen asumió la dirección de 2000 a 2004; para entonces, el Instituto contaba con una planta académica de 36 investigadores de tiempo completo y catorce técnicos académicos. Todos los investigadores trabajaban al menos en un proyecto individual y participaban en promedio en casi dos proyectos colectivos. A este respecto se menciona en el folleto La investigación humanística y social en la UNAM, que:

En todo caso, la investigación que se lleva a cabo en el IIFs puede ser calificada como investigación de frontera. Tanto las investigaciones que participan en los debates más actuales del campo filosófico, como los estudios en temas clásicos o históricos, se reconocen y valoran en México y en el extranjero, como contribuciones de alto nivel académico. ${ }^{28}$

En cuanto a la docencia, los investigadores impartieron en el período, en promedio, dos cursos cada uno, esto es, alrededor de setenta cursos, dos terceras partes de los cuales se concentraron en el posgrado. En cuanto a las actividades académicas, en este período continuaron tanto los seminarios de investigadores y becarios como los simposios internacionales de filosofía, dedicados a gran variedad de temas y problemas filosóficos; pero lo más relevante, sin duda, fue el aumento en los seminarios de área debido al fortalecimiento de las áreas que para ese momento llegaron a trece al incorporarse la filosofía de la religión. En relación con las actividades docentes y de difusión, además de las conferencias, seminarios y talleres, en el Instituto se organizó en 2003, con el apoyo de la Coordinación de Humanidades y la Academia Mexicana de las Ciencias, el Diplomado en Lógica, cuyas ediciones sucesivas llevaron a la creación de la Academia de la Lógica, que acoge a los profesores del área en todo el país.

La biblioteca "García Máynez" contaba ya con un acervo de 36000 volúmenes con un ritmo anual de crecimiento de 1500 a 2000 nuevos títulos y podía consultarse en red a través de la página del Instituto. La hemeroteca tenía ya su propio espacio y estaba integrada por 353 títulos vigentes de publicaciones periódicas; se habían coleccionado 7030 volúmenes de publicaciones especializadas. Por estas razones se podía decir ya, sin sombra de duda, que la biblioteca del Instituto de

${ }^{28}$ La investigación humanística y social en la UNAM, Coordinación de Humanidades, unAm, México, 2003, p. 73.

Diánoia, vol. LV, no. 64 (mayo 2010). 
Investigaciones Filosóficas era la más importante biblioteca especializada en filosofía de Hispanoamérica.

En general, las publicaciones siguieron su curso, tanto las periódicas como las colecciones existentes, y se informó que el promedio de publicaciones entre los investigadores había ascendido a un libro y medio anual por investigador.

\section{La etapa actual}

Del año 2004 a la fecha, la dirección del Instituto ha estado a cargo del doctor Guillermo Hurtado, quien considera que el principal objetivo del Instituto es "que la Universidad Nacional y por añadidura nuestro país deben tener un espacio académico dedicado al cultivo exclusivo de la investigación filosófica”. ${ }^{29}$ Esto, en su opinión, es seguir la línea de los fundadores y de quienes consolidaron la existencia del Instituto, e implica mantener los estrictos criterios de profesionalismo y de alto nivel internacional, así como el carácter de comunidad académica a través del diálogo metodológicamente sustentado en un lenguaje filosófico común. Pero avanza: "Me parece que nuestro proyecto institucional debe ser preservado, fortalecido y extendido. No sólo debemos realizar esfuerzos para tener mayor influencia en la filosofía mexicana, sino también para tenerla en la cultura nacional en su conjunto."30

Un rasgo fundamental de la gestión de Guillermo Hurtado es haber revitalizado el Claustro del personal académico al establecer un mecanismo objetivo para analizar en detalle la situación del Instituto, tanto de las áreas de investigación como de las de biblioteca, cómputo, administración, etc., lo cual dio por resultado: "un documento que fijó objetivos y criterios para el desarrollo del Instituto para el período 20042008". ${ }^{31}$ Dentro del marco de este amplio ejercicio de democratización, el Consejo Interno del Instituto elaboró los criterios para opinar sobre contrataciones y promociones de investigadores, revisó el Reglamento Interno y lo modificó para garantizar la representación de los técnicos académicos.

En el año 2008, el informe reporta 42 investigadores, poco más del 55 por ciento son hombres y el 45 por ciento mujeres, con un promedio general de edad de 52 años. Asimismo, se reportan diecisiete áreas de investigación al distinguir entre ética y ética aplicada; lógica, filosofía

${ }^{29}$ G. Hurtado, Cuarto informe de actividades (2004-2008), p. 1.

${ }^{30}$ Ibid., p. 2.

${ }^{31}$ Ibid. 
de la lógica y filosofía de la matemáticas; así como entre metafísica y ontología. Esta diversidad refleja no sólo la variedad en el quehacer filosófico, sino que el Instituto sigue siendo pionero en la investigación de importantes áreas del conocimiento a nivel nacional. Por otra parte, se menciona que en el Instituto se desarrollan catorce proyectos colectivos, la mayor parte de los cuales reciben financiamiento externo, y esto indica el fortalecimiento del trabajo en equipo. Actualmente, todos los investigadores están en los programas de estímulos, tanto internos como externos, y es de señalarse que las tres cuartas partes están en los niveles superiores. Por último, doce investigadores se hicieron acreedores a más de catorce premios y distinciones tanto nacionales como extranjeras.

El ritmo de la producción es de aproximadamente veintidós libros (individuales y colectivos), alrededor de cien capítulos en libros y cincuenta artículos en revistas y cerca de veinte reseñas; tal es la constante anual reportada y se especifica que el 50 por ciento de estos productos fueron publicados en el extranjero; con esto se subraya el impacto de la investigación del Instituto a nivel internacional.

En cuanto a los técnicos académicos, el Instituto cuenta con diecisiete, todos en el programa de estímulos interno. Por otra parte, de 2004 a 2008 ingresaron doce becarios posdoctorales, programa que ha sido muy benéfico para el fortalecimiento de las diversas áreas y que habla también del prestigio del Instituto en el extranjero.

La intensa actividad académica de nivel internacional se refleja en las más de cien reuniones (simposios, coloquios, encuentros, etc.) que se llevaron a cabo en el Instituto en este período, donde participaron al menos igual número de invitados extranjeros, entre los más destacados filósofos actuales. ${ }^{32}$ Además, se fundó la Asociación Latinoamericana de Filosofía Analítica.

En cuanto al trabajo académico a nivel nacional, el Instituto ha fomentado el trabajo interdisciplinario, tanto a través del posgrado en filosofía de la ciencia que nació en el Instituto, como por la participación de los investigadores en tres proyectos interdisciplinarios que tienden a constituirse en seminarios institucionales. Por otra parte, se mantienen los convenios con las universidades de Zacatecas y Michoacán para el apoyo a la docencia y la investigación, pero sobre todo con la fundación del Centro Peninsular en Humanidades y Ciencias Sociales (CEPHYCIS) de Mérida, al que se han trasladado algunos investigadores del Instituto y es el eje para el desarrollo de la filosofía en la región.

${ }^{32}$ Véase ibid., p. 6. 
En relación con la docencia, el informe consigna que en 2007 se impartieron 66 asignaturas (veintidós en licenciatura y 33 en posgrado) para un promedio de 1.6 asignaturas por investigador. Asimismo, se refieren 124 tesis terminadas o en proceso, eso es un promedio de 3.02 tesis por investigador. En apoyo a la labor docente se ampliaron las instalaciones con tres aulas y cubículos para estudiantes asociados.

A raíz de la renovación en 2005 del Programa de Estudiantes Asociados, para 2008 se contaba con 34 estudiantes tanto de México como de otros países de Latinoamérica, lo que habla del interés de la institución por su formación profesional.

En cuanto a la labor de difusión, se cuenta con el equipo para conferencias a distancia que permitió transmitir a Mérida un curso sobre Filosofía Antigua dictado en el Instituto; además, se impartieron los diplomados en lógica, en filosofía, historia y docencia de la química y en bioética. Asimismo, atendiendo a los problemas sociales ingentes, se desarrolló un coloquio sobre el aborto; se constituyó un grupo de discusión sobre la reforma al código penal y se grabaron varios programas de televisión para la difusión de la filosofía.

Por lo que toca al programa editorial del Instituto, Guillermo Hurtado señala que: "A lo largo de 68 años de existencia del Instituto, hemos publicado más de medio millar de títulos. Pocas, muy pocas, editoriales en lengua española tienen un catálogo de filosofía que pueda equipararse por su cantidad y calidad, con el nuestro."33

Entre 2004 y 2008 se publicaron 36 libros y veinticuatro números de revistas. En 2005, Diánoia cumplió cincuenta años de publicación continua, por lo que en colaboración con el Fondo de Cultura Económica se realizó un coloquio internacional y en 2007 se inauguró la página electrónica de esta revista. Por su parte, la revista Crítica cuenta actualmente con dirección propia, lo que permitió eliminar los rezagos y contar con un 40 por ciento más de colaboraciones. Hay que señalar que es la única revista latinoamericana que aparece en la lista de revistas científicas de excelencia; en 2005 lanzó su página electrónica. Al cumplir cuarenta años, en 2007, se organizó un Simposio Iberoamericano de Filosofía Analítica.

Durante toda su gestión, el doctor Hurtado ha promovido la realización anual de una Feria del Libro Filosófico que ha tenido importantes resultados, no sólo para dar a conocer la producción del Instituto y sus investigadores, sino para conjuntar un importante número de casas

${ }^{33}$ Ibid. p. 10.

Diánoia, vol. LV, no. 64 (mayo 2010). 
editoriales que se ocupan de temas filosóficos para que muestren su más reciente producción en el área.

La biblioteca "García Máynez" creció durante el período de referencia hasta contar con 33112 títulos de libros y un total de 41672 ejemplares. A su vez, la hemeroteca llegó a 542 títulos de revistas para un total de 38357 fascículos. Además, se adquirieron varios libros electrónicos y diversas guías de información en línea. El espacio físico se amplió para dar cabida a la colección del Fondo Reservado.

En cuanto al proyecto de la Bibliografía Filosófica Mexicana, se dio cima con gran éxito a la primera etapa, que en un disco compacto guarda cincuenta años de la totalidad de la producción filosófica en México en la segunda mitad del siglo Xx, con 27660 registros. Por otro lado, en 2005 se digitalizó y se difundió en disco compacto el archivo "Samuel Ramos".

En la actualidad, el Departamento de Cómputo se ha hecho tan indispensable como omnipresente. Así, apoya a la investigación y la docencia; a los estudiantes asociados; a la biblioteca y a las secretarías académica, técnica y administrativa; al Departamento de Publicaciones, a los servicios secretariales y a las actividades académicas nacionales e internacionales; se ocupa de la puesta al día del sitio web del Instituto, de las páginas de sus investigadores y de diversos servicios y revistas, y con su labor facilita la comunicación constante entre colegas nacionales y extranjeros, etc. De esta manera, dicho departamento crece y se mantiene constantemente actualizado.

En suma, el Instituto no sólo crece, sino que se propone día a día nuevas y más complejas metas, por lo que se mantiene a la vanguardia de la investigación filosófica en el país. ${ }^{34}$

\section{ANEXOS}

El Instituto de Investigaciones Filosóficas y los posgrados de filosofía y de filosofía de la ciencia

El Instituto de Investigaciones Filosóficas figura como entidad participante tanto en el posgrado en filosofía como en el de filosofía de la ciencia. Ello se traduce en que los alumnos de estos posgrados cuentan

${ }^{34}$ Quiero hacer expreso mi agradecimiento al maestro Miguel Gama, jefe de la Biblioteca "Eduardo García Máynez", sin cuya colaboración no me hubiera sido posible dar cima a este trabajo. Asimismo, agradezco a la Coordinación del Posgrado en Filosofia y a la Coordinación del Posgrado en Filosofía de la Ciencia que me hayan proporcionado los datos estadísticos que aquí presento y resumo.

Diánoia, vol. LV, no. 64 (mayo 2010). 
con servicios completos de biblioteca, de sala de cómputo, así como con espacios para cursos, y en el caso del posgrado en filosofía de la ciencia, con recursos humanos para el apoyo del programa y con espacios para su coordinación. Además de estos aspectos formales, una gran cantidad de los investigadores ofrecen cursos en ambos posgrados y forman parte de los respectivos padrones de tutores.

\section{Algunos números representativos}

En cuanto al posgrado en filosofía:

1. La gráfica 1 (p. 223), que se refiere al origen de los estudiantes (nacionales o extranjeros) entre 2000 y 2008, muestra una creciente tendencia de la demanda de estudios de maestría por parte de los alumnos nacionales, que aumentó de diecinueve en el año 2000 a 82 en 2008, en tanto que los extranjeros fluctuaron entre dos y cinco durante el mismo período.

2. La demanda de maestría por parte de alumnos con licenciatura en filosofía alcanzó sus mayores niveles en 2001 (48 estudiantes) y en 2007 (57 estudiantes), según se muestra en la gráfica 2, mientras que los que tienen una licenciatura diferente se elevaron de dos estudiantes en el 2000, a veinticinco en 2007. Véase la gráfica 2 (p. 223)

3. En cuanto a la demanda de estudios de doctorado, el comportamiento es bastante similar: según la gráfica 3 (p. 224), en 2000 ingresaron quince alumnos con licenciatura en filosofía y en 2007 el número se elevó a treinta. En tanto que la cifra de alumnos con una licenciatura diferente se elevó de dos en el año 2000 a once en 2007.

4. En promedio, del año 2000 al 2008 el posgrado en filosofía (maestría y doctorado) tuvo un 94 por ciento de alumnos nacionales frente a un 6 por ciento de alumnos extranjeros (gráfica 4, (p. 224)).

5. Para el programa de posgrado en filosofía (maestría y doctorado) se percibe un aumento constante en las solicitudes que van de cuarenta en 2000, a 213 en 2008 (gráfica 5, p. (p. 225)).

6. Según la gráfica 6 (p. 226), en conjunto, los estudiantes que ingresan a maestría y que provienen de la UNAM guardan una proporción semejante con los que provienen de otras instituciones, 
salvo en el caso de los años 2004, 2007 y 2008, en que hubo más alumnos provenientes de la UNAM y que contrasta con los años 2002, 2005 y 2006, en que hubo más alumnos provenientes de otras instituciones.

7. En el caso del doctorado se aprecia en casi todos los años (2000 a 2008) una mayoría de alumnos de la UNAM, salvo en 2002, cuando ingresaron más alumnos de otras instituciones (cfr. la gráfica 7, p. 226).

8. En cuanto a la gráfica de ingreso por generación (cfr. la gráfica 8 , p. 227), puede verse en ella cómo el ingreso a maestría supera en todos los años el ingreso al doctorado en forma notable, salvo en el año 2000, que fue muy equilibrado.

9. En la gráfica de estudiantes becados de maestría se aprecia cómo el número de becados por CONACYT ha ido en constante aumento, de diez en 2002 a 66 en 2007 (gráfica 9, p. 227).

10. En cuanto a los becarios de doctorado, la cifra va de siete en 2000 a treinta en 2007 becados por CONACYT (gráfica 10, p. 228).

11. En lo que respecta al número de estudiantes por género, según la gráfica 11 (p. 228), en el posgrado en filosofía hay 62 por ciento de varones y 38 por ciento de mujeres.

12. Por último, en lo que corresponde a los alumnos graduados de 1995 a 2006, en maestría se nota un constante aumento que va de seis alumnos graduados en 1995 a veintiséis en 2006. En lo que toca a los de doctorado, el comportamiento es más irregular y alcanza la cifra mayor en 2000, cuando se graduaron dieciocho estudiantes frente a once de 1995 y dieciséis de 2006. Véase la gráfica 12 (p. 229).

En cuanto al posgrado en filosofía de la ciencia, los alumnos de maestría y doctorado graduados por generación (gráfica 13, p. 230) son:

De la generación 2003: 91.3 por ciento

De la generación 2004: 85 por ciento

De la generación 2005: 84.2 por ciento

De la generación 2006: se proyecta el 100 por ciento 


\section{Gráfica 1}

Número y porcentaje de estudiantes provenientes de instituciones nacionales

o extranjeras (maestría)

\begin{tabular}{|l|c|c|c|c|c|c|c|c|c|c|c|c|c|c|c|c|c|c|}
\hline & 2000 & $\%$ & 2001 & $\%$ & 2002 & $\%$ & 2003 & $\%$ & 2004 & $\%$ & 2005 & $\%$ & 2006 & $\%$ & 2007 & $\%$ & 2008 & $\%$ \\
\hline Nacionales & 19 & 90 & 48 & 96 & 46 & 94 & 47 & 98 & 56 & 97 & 41 & 95 & 45 & 93.75 & 77 & 93 & 82 & 100 \\
\hline Extranjeras & 2 & 10 & 2 & 4 & 3 & 6 & 1 & 2 & 2 & 3 & 2 & 5 & 3 & 6.25 & 5 & 7 & 0 & 0 \\
\hline
\end{tabular}

Número de estudiantes provenientes de instituciones nacionales o extranjeras (maestría)

Nacionales

Extranjeras

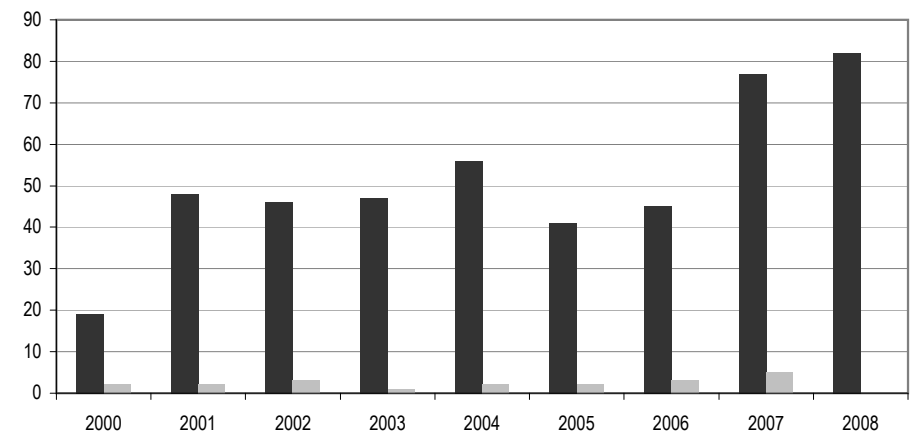

Gráfica 2

Número y porcentaje de estudiantes que ingresan anualmente al programa por licenciatura de procedencia (maestría)

\begin{tabular}{|l|c|c|c|c|c|c|c|c|c|c|c|c|c|c|c|c|c|c|}
\cline { 2 - 15 } \multicolumn{1}{c|}{} & 2000 & $\%$ & 2001 & $\%$ & 2002 & $\%$ & 2003 & $\%$ & 2004 & $\%$ & 2005 & $\%$ & 2006 & $\%$ & 2007 & $\%$ & 2008 & $\%$ \\
\hline Filosofia & 19 & 90 & 48 & 96 & 44 & 90 & 33 & 69 & 46 & 79 & 28 & 65 & 36 & 75 & 57 & 69 & 54 & 75 \\
\hline Otra & 2 & 10 & 2 & 4 & 5 & 10 & 15 & 31 & 12 & 21 & 15 & 35 & 12 & 25 & 25 & 31 & 18 & 25 \\
\hline
\end{tabular}

Número de estudiantes que ingresan anualmente por licenciatura de procedencia (maestría)
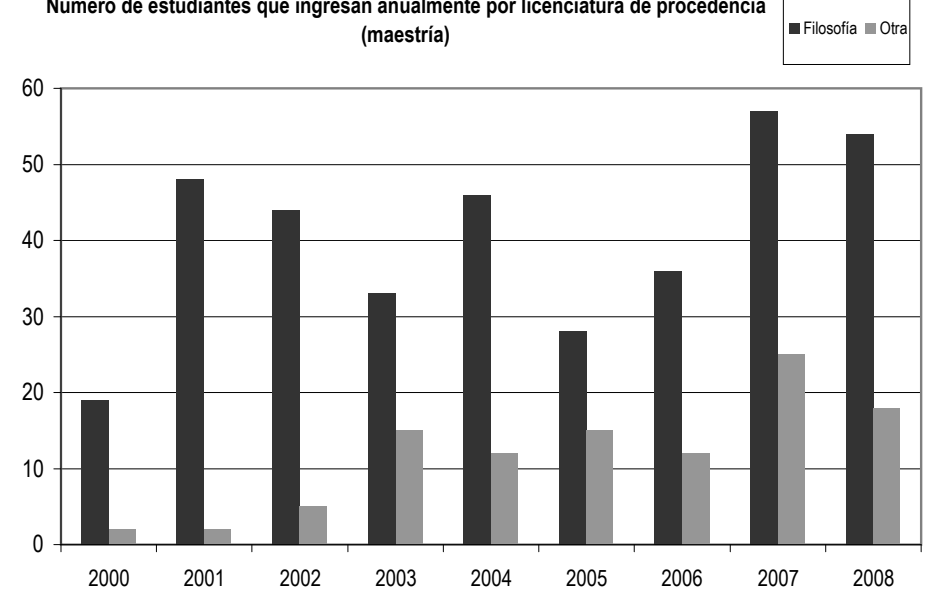

Diánoia, vol. LV, no. 64 (mayo 2010). 


\section{Gráfica 3}

Número y porcentaje de estudiantes que ingresan anualmente al programa por licenciatura de procedencia (doctorado)

\begin{tabular}{|c|c|c|c|c|c|c|c|c|c|c|c|c|c|c|c|c|c|c|}
\hline & 2000 & $\%$ & 2001 & $\%$ & 2002 & $\%$ & 2003 & $\%$ & 2004 & $\%$ & 2005 & $\%$ & 2006 & $\%$ & 2007 & $\%$ & 2008 & $\%$ \\
\hline Filosofia & 15 & 84 & 12 & 92 & 10 & 71 & 13 & 76 & 10 & 83 & 7 & 100 & 15 & 88.23 & 30 & 73 & 22 & 73 \\
\hline Otra & 2 & 16 & 1 & 8 & 4 & 19 & 4 & 24 & 2 & 17 & 0 & 0 & 2 & 11.77 & 11 & 27 & 8 & 27 \\
\hline
\end{tabular}

Número de estudiantes que ingresan anualmente por licenciatura de procedencia (doctorado) $\square$ Filosofía $\quad$ Otra

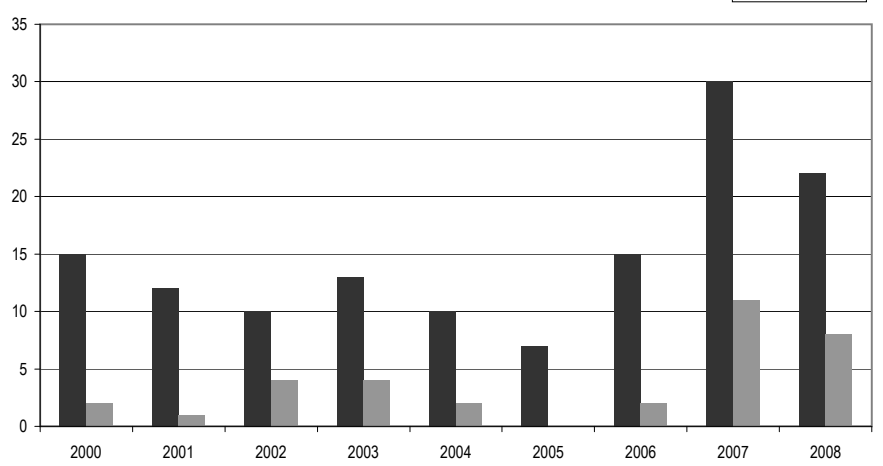

Gráfica 4

Número y porcentaje de estudiantes por nacionalidad (maestría)

\begin{tabular}{|l|l|l|l|l|l|l|l|l|l|l|l|l|l|l|l|l|l|}
\hline 2000 & $\%$ & 2001 & $\%$ & 2002 & $\%$ & 2003 & $\%$ & 2004 & $\%$ & 2005 & $\%$ & 2006 & $\%$ & 2007 & $\%$ & 2008 & $\%$ \\
\hline
\end{tabular}

\begin{tabular}{|c|c|c|c|c|c|c|c|c|c|c|c|c|c|c|c|c|c|c|} 
& 2000 & $\%$ & 2001 & $\%$ & 2002 & $\%$ & 2003 & $\%$ & 2004 & $\%$ & 2005 & $\%$ & 2006 & $\%$ & 2007 & $\%$ & 2008 & $\%$ \\
\hline Mexicana & 19 & 90 & 48 & 96 & 45 & 92 & 48 & 100 & 56 & 97 & 41 & 95 & 45 & 93.75 & 76 & 93 & 81 & 98 \\
\hline Extranjera & 2 & 10 & 2 & 4 & 4 & 8 & 0 & 0 & 2 & 3 & 2 & 5 & 3 & 6 & 6 & 7 & 1 & 2 \\
\hline
\end{tabular}

Número y porcentaje de estudiantes por nacionalidad (doctorado)

\begin{tabular}{|l|l|l|l|l|l|l|l|l|l|l|l|l|l|l|l|l|l|}
\hline 2000 & $\%$ & 2001 & $\%$ & 2002 & $\%$ & 2003 & $\%$ & 2004 & $\%$ & 2005 & $\%$ & 2006 & $\%$ & 2007 & $\%$ & 2008 & $\%$ \\
\hline
\end{tabular}

\begin{tabular}{|c|c|c|c|c|c|c|c|c|c|c|c|c|c|c|c|c|c|c|}
\hline Mexicana & 11 & 84 & 13 & 100 & 12 & 86 & 17 & 100 & 11 & 92 & 7 & 100 & 17 & 100 & 38 & 93 & 27 & 90 \\
\hline Extranjera & 2 & 16 & 0 & 0 & 2 & 14 & 0 & 0 & 1 & 8 & 0 & 0 & 0 & 0 & 3 & 7 & 3 & 10 \\
\hline
\end{tabular}

Número y porcentaje de estudiantes por nacionalidad. Totales

\begin{tabular}{|l|l|l|l|l|l|l|l|l|l|l|l|l|l|l|l|l|l|}
\hline 2000 & $\%$ & 2001 & $\%$ & 2002 & $\%$ & 2003 & $\%$ & 2004 & $\%$ & 2005 & $\%$ & 2006 & $\%$ & 2007 & $\%$ & 2008 & $\%$ \\
\hline
\end{tabular}

\begin{tabular}{|c|c|c|c|c|c|c|c|c|c|c|c|c|c|c|c|c|c|c|}
\hline Mexicana & 30 & 88 & 61 & 97 & 57 & 90 & 65 & 100 & 67 & 96 & 48 & 96 & 62 & 93.38 & 114 & 93 & 108 & 96 \\
\hline Extranjera & 4 & 12 & 2 & 3 & 6 & 10 & 0 & 0 & 3 & 4 & 2 & 4 & 3 & 7 & 9 & 7 & 4 & 4 \\
\hline
\end{tabular}

\begin{tabular}{c|c|c|}
\hline \multirow{3}{*}{ Promedio } & Mexicanos & $94 \%$ \\
\cline { 2 - 3 } & Extranjeros & $6 \%$ \\
\hline
\end{tabular}

Porcentaje de estudiantes por nacionalidad

- Mexicanos Extranjeros

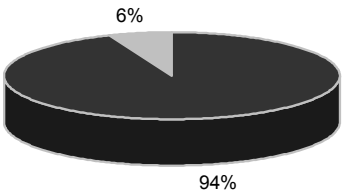

Diánoia, vol. LV, no. 64 (mayo 2010). 


\section{Gráfica 5}

\section{Alumnos}

Número de aspirantes que solicitan anualmente su ingreso al Programa de Maestría

\begin{tabular}{|l|c|c|c|c|c|c|c|c|c|}
\hline Generación & 2000 & 2001 & 2002 & 2003 & 2004 & 2005 & 2006 & 2007 & 2008 \\
\hline Número & 24 & 71 & 73 & 92 & 113 & 67 & 91 & 114 & 154 \\
\hline
\end{tabular}

Número de aspirantes que solicitan anualmente su ingreso al Programa de Doctorado

\begin{tabular}{|l|c|c|c|c|c|c|c|c|c|}
\hline Generación & 2000 & 2001 & 2002 & 2003 & 2004 & 2005 & 2006 & 2007 & 2008 \\
\hline Número & 16 & 22 & 23 & 28 & 30 & 17 & 21 & 50 & 59 \\
\hline
\end{tabular}

Número de aspirantes que solicitan anualmente su ingreso a los programas de maestría y doctorado (totales)

\begin{tabular}{|l|c|c|c|c|c|c|c|c|c|}
\hline Generación & 2000 & 2001 & 2002 & 2003 & 2004 & 2005 & 2006 & 2007 & 2008 \\
\hline Número & 40 & 93 & 96 & 120 & 143 & 84 & 112 & 164 & 213 \\
\hline
\end{tabular}

Número total de solicitudes para ingresar a los programas recibidas anualmente

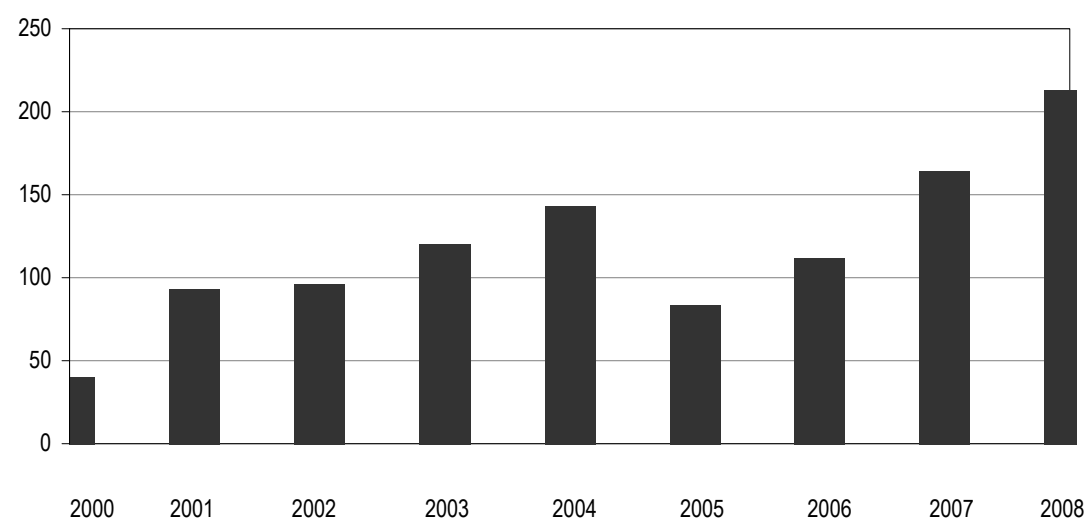




\section{Gráfica 6}

Número y porcentaje de estudiantes provenientes de la UNAM (maestría)

\begin{tabular}{|l|c|c|c|c|c|c|c|c|c|c|c|c|c|c|c|c|c|c|}
\multicolumn{1}{c|}{} & 2000 & $\%$ & 2001 & $\%$ & 2002 & $\%$ & 2003 & $\%$ & 2004 & $\%$ & 2005 & $\%$ & 2006 & $\%$ & 2007 & $\%$ & 2008 & $\%$ \\
\hline UNAM & 14 & 66.6 & 25 & 50 & 22 & 45 & 24 & 50 & 32 & 55 & 21 & 49 & 21 & 44 & 42 & 51 & 43 & 60 \\
\hline Otra & 7 & 33.3 & 25 & 50 & 27 & 55 & 24 & 50 & 26 & 45 & 22 & 51 & 27 & 56 & 40 & 49 & 29 & 40 \\
\hline
\end{tabular}

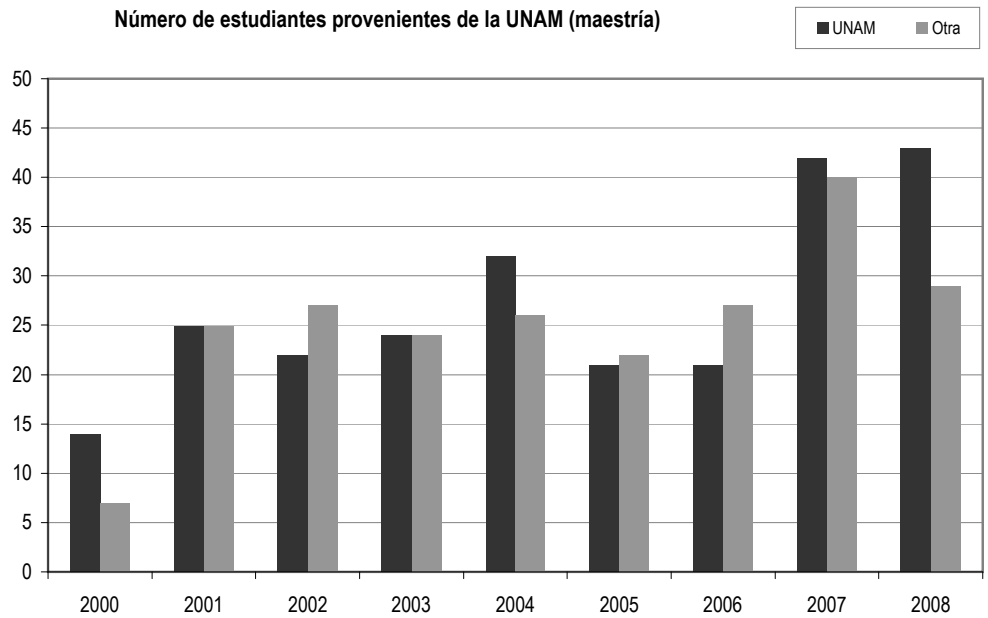

\section{Gráfica 7}

Número y porcentaje de estudiantes provenientes de la UNAM (doctorado)

\begin{tabular}{|c|c|c|c|c|c|c|c|c|c|c|c|c|c|c|c|c|c|c|}
\hline & 2000 & $\%$ & 2001 & $\%$ & 2002 & $\%$ & 2003 & $\%$ & 2004 & $\%$ & 2005 & $\%$ & 2006 & $\%$ & 2007 & $\%$ & 2008 & $\%$ \\
\hline UNAM & 9 & 53 & 7 & 54 & 6 & 43 & 10 & 59 & 7 & 58 & 4 & 57 & 9 & 52.94 & 28 & 68 & 24 & 80 \\
\hline Otra & 8 & 47 & 6 & 46 & 8 & 57 & 7 & 41 & 5 & 42 & 3 & 43 & 8 & 47.06 & 13 & 32 & 6 & 20 \\
\hline
\end{tabular}

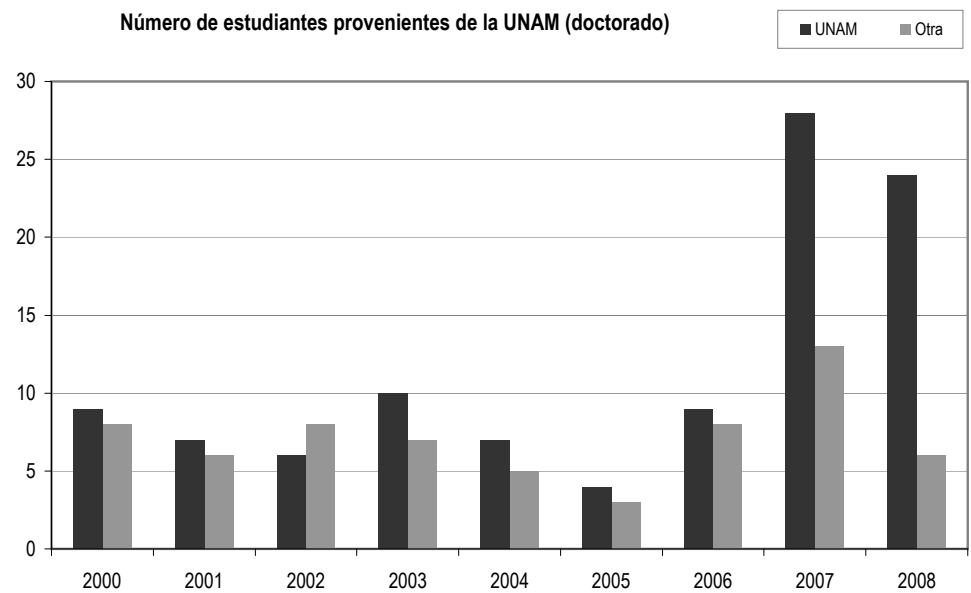

Diánoia, vol. LV, no. 64 (mayo 2010). 
Gráfica 8

Número de estudiantes de nuevo ingreso por generación

\begin{tabular}{|l|c|c|c|c|c|c|c|c|c|}
\hline & 2000 & 2001 & 2002 & 2003 & 2004 & 2005 & 2006 & 2007 & 2008 \\
\hline Maestría & 21 & 50 & 49 & 48 & 58 & 43 & 48 & 82 & 72 \\
\hline Doctorado & 17 & 13 & 14 & 17 & 12 & 7 & 17 & 41 & 30 \\
\hline Totales & 38 & 63 & 63 & 65 & 70 & 50 & 65 & 123 & 102 \\
\hline
\end{tabular}

Número de estudiantes de nuevo ingreso por generación

$$
\text { Maestria } \quad \text { Doctorado } \quad \text { Totales }
$$

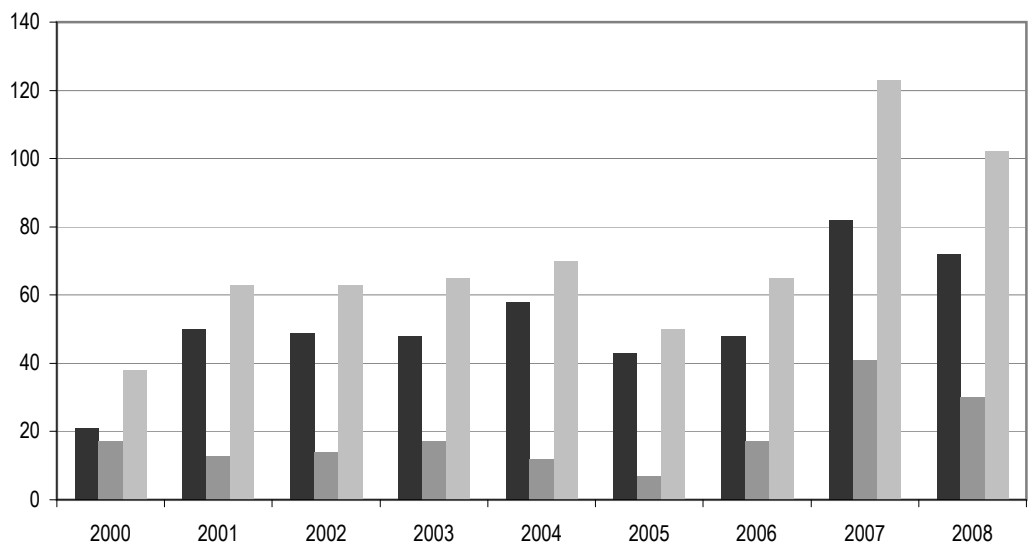

Gráfica 9

Número de estudiantes de nuevo ingreso becados en maestría

\begin{tabular}{|c|c|c|c|c|c|c|c|c|c|c|c|c|c|c|c|c|}
\hline & 2000 & $\%$ & 2001 & $\%$ & 2002 & $\%$ & 2003 & $\%$ & 2004 & $\%$ & 2005 & $\%$ & 2006 & $\%$ & 2007 & $\%$ \\
\hline UNAM & 4 & 19 & 7 & 15 & 2 & 4 & 4 & 8 & 10 & 17 & 10 & 21.3 & 4 & 8.3 & 2 & 2 \\
\hline CONACYT & 10 & 48 & 26 & 54 & 24 & 52 & 38 & 76 & 45 & 76 & 37 & 78.7 & 39 & 81.25 & 66 & 80 \\
\hline
\end{tabular}

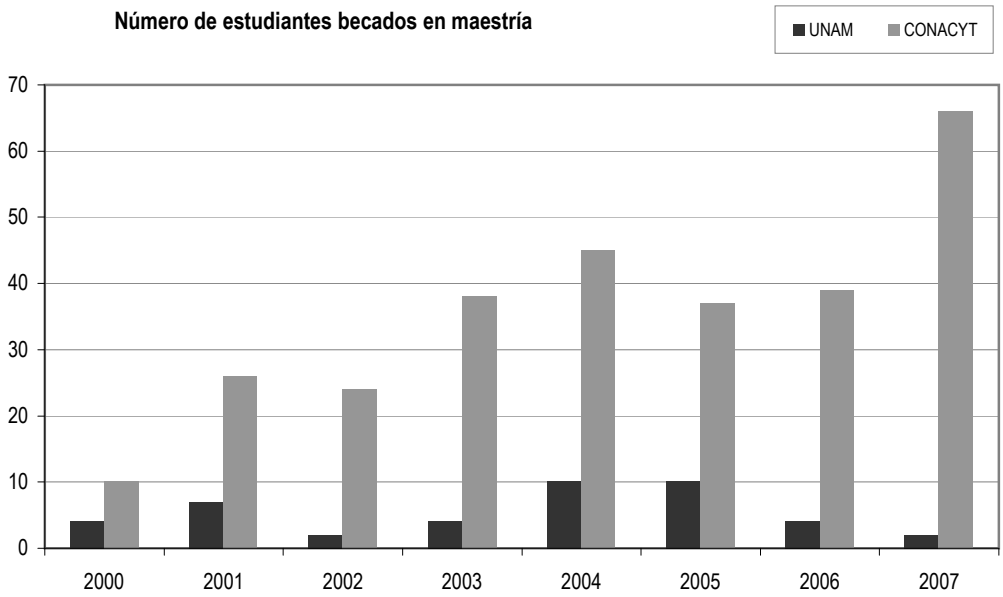

Diánoia, vol. LV, no. 64 (mayo 2010). 


\section{Gráfica 10}

Número de estudiantes de nuevo ingreso becados en doctorado

\begin{tabular}{|c|c|c|c|c|c|c|c|c|c|c|c|c|c|c|c|c|}
\hline & 2000 & $\%$ & 2001 & $\%$ & 2002 & $\%$ & 2003 & $\%$ & 2004 & $\%$ & 2005 & $\%$ & 2006 & $\%$ & 2007 & $\%$ \\
\hline \begin{tabular}{|l} 
UNAM \\
\end{tabular} & 1 & 8 & 6 & 46 & 1 & 7 & 3 & 17 & 1 & 8 & 0 & 0 & 1 & 5 & 1 & 2 \\
\hline CONACYT & 7 & 54 & 4 & 31 & 9 & 64 & 5 & 28 & 9 & 75 & 6 & 86 & 10 & 58 & 30 & 59 \\
\hline Otra & 1 & 8 & 0 & 0 & 0 & 0 & 0 & 0 & 0 & 0 & 0 & 0 & 1 & 5 & 0 & 0 \\
\hline
\end{tabular}
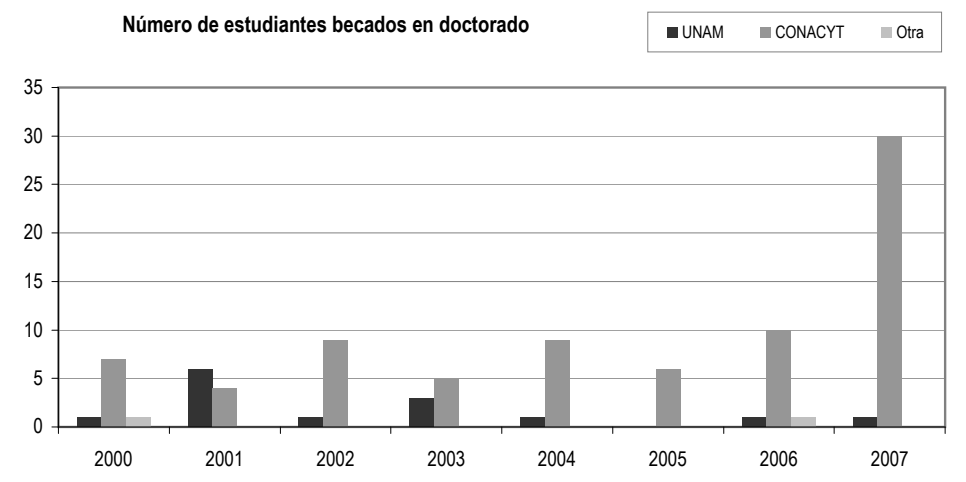

\section{Gráfica 11}

Número de estudiantes por género (maestría)

\begin{tabular}{|c|c|c|c|c|c|c|c|c|c|c|c|c|c|c|c|c|c|c|}
\hline & 2000 & $\%$ & 2001 & $\%$ & 2002 & $\%$ & 2003 & $\%$ & 2004 & $\%$ & 2005 & $\%$ & 2006 & $\%$ & 2007 & $\%$ & 2008 & $\%$ \\
\hline \begin{tabular}{|l} 
Femenino \\
\end{tabular} & 11 & 52 & 19 & 38 & 21 & 43 & 16 & 33 & 24 & 41 & 22 & 51 & 22 & 46 & 35 & 43 & 21 & 29 \\
\hline Masculino & 10 & 48 & 31 & 62 & 28 & 57 & 32 & 67 & 34 & 59 & 21 & 49 & 26 & 54 & 47 & 57 & 51 & 71 \\
\hline
\end{tabular}

Número de estudiantes por género (doctorado)

\begin{tabular}{|c|c|c|c|c|c|c|c|c|c|c|c|c|c|c|c|c|c|c|}
\hline \multicolumn{19}{|c|}{ Número de estudiantes por género (doctorado) } \\
\hline & 2000 & $\%$ & 2001 & $\%$ & 2002 & $\%$ & 2003 & $\%$ & 2004 & $\%$ & 2005 & $\%$ & 2006 & $\%$ & 2007 & $\%$ & 2008 & $\%$ \\
\hline & 5 & 38 & 6 & 46 & 8 & 57 & 6 & 35 & 3 & 25 & 3 & 37 & 4 & 24 & 12 & 29 & 3 & 10 \\
\hline Masculino & 8 & 62 & 7 & 54 & 6 & 43 & 11 & 65 & 9 & 75 & 5 & 63 & 13 & 76 & 29 & 71 & 27 & 90 \\
\hline
\end{tabular}

\begin{tabular}{|c|c|c|c|c|c|c|c|c|c|c|c|c|c|c|c|c|c|c|}
\hline \multicolumn{19}{|c|}{ Número de estudiantes por género. Totales } \\
\hline & 2000 & $\%$ & 2001 & $\%$ & 2002 & $\%$ & 2003 & $\%$ & 2004 & $\%$ & 2005 & $\%$ & 2006 & $\%$ & 2007 & $\%$ & 2008 & $\%$ \\
\hline Femenino & 16 & 47 & 25 & 40 & 29 & 46 & 22 & 34 & 27 & 39 & 25 & 49 & 26 & 40 & 47 & 38 & 24 & 23 \\
\hline Masculino & 18 & 53 & 38 & 60 & 34 & 54 & 43 & 66 & 43 & 61 & 26 & 51 & 39 & 60 & 76 & 62 & 78 & 77 \\
\hline
\end{tabular}

\begin{tabular}{|l|c|}
\hline General & $\%$ \\
\hline F & 38 \\
\hline M & 62 \\
\hline
\end{tabular}

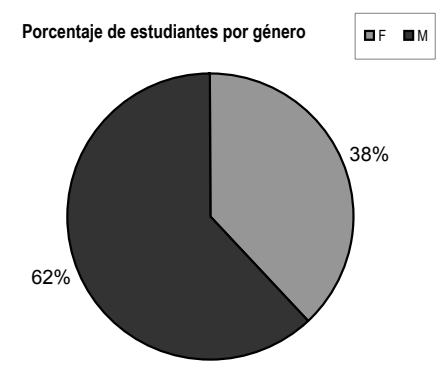

Diánoia, vol. LV, no. 64 (mayo 2010). 
Gráfica 12

Alumnos graduados 1995-2006

\begin{tabular}{|l|c|c|c|c|c|c|c|c|c|c|c|c|}
\hline & 1995 & 1996 & 1997 & 1998 & 1999 & 2000 & 2001 & 2002 & 2003 & 2004 & 2005 & 2006 \\
\hline Maestría & 6 & 6 & 5 & 7 & 8 & 13 & 8 & 19 & 14 & 15 & 23 & 26 \\
\hline Doctorado & 11 & 7 & 9 & 16 & 5 & 18 & 4 & 7 & 14 & 10 & 9 & 16 \\
\hline
\end{tabular}

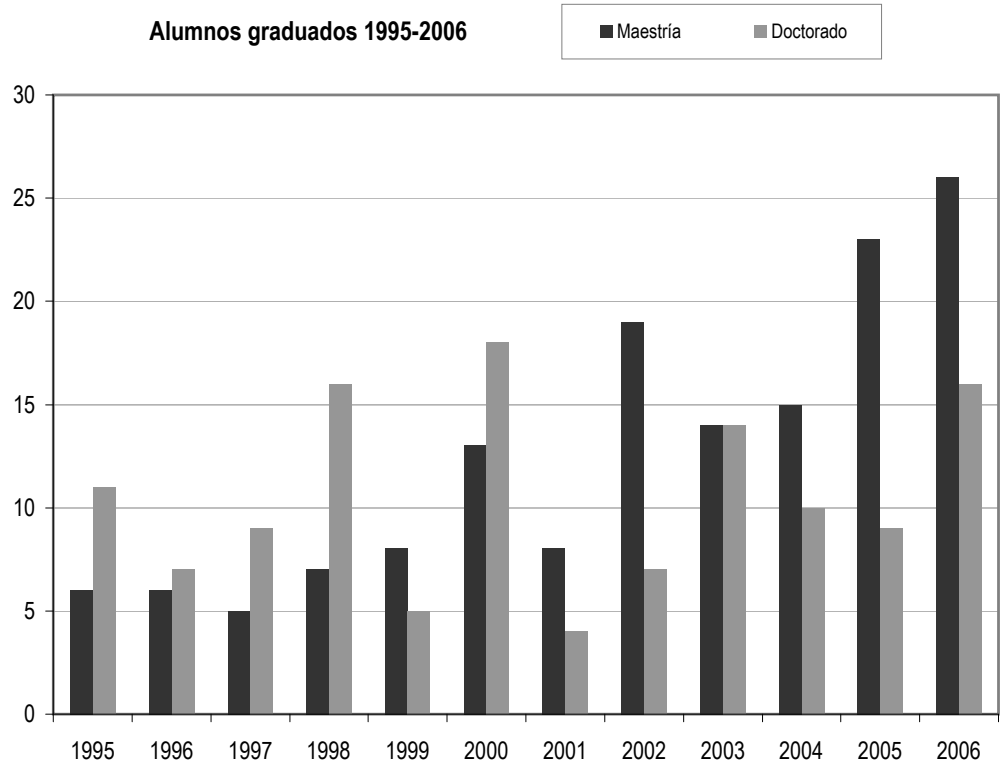

Diánoia, vol. LV, no. 64 (mayo 2010). 
Gráfica 13

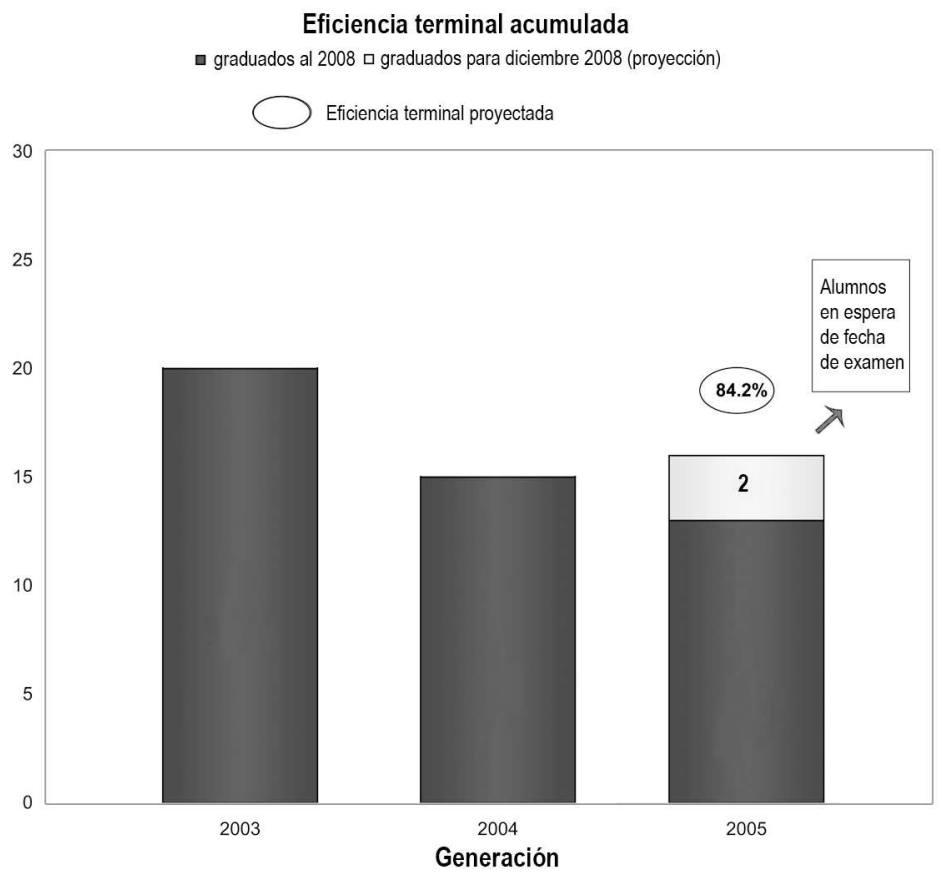

\section{BIBLIOGRAFÍA}

Catálogo histórico de publicaciones del Instituto de Investigaciones Filosóficas. 1940-2007, comp. Carolina Celorio, Instituto de Investigaciones FilosóficasUNAM, México, 2008.

Coordinación de Humanidades, Instituto de Investigaciones Filosóficas, folleto, Coordinación de Humanidades-UnAM, México, 1992.

_- La investigación humanística y social en la UNAM, folleto, Coordinación de Humanidades-unAm, México, 2003.

García Máynez, E., "Breve historia del Centro de Estudios Filosóficos", Dianoia. Anuario de Filosofía, vol. 12, 1966, pp. 240-248.

Hurtado, G., Cuarto informe de actividades (2004-2008), Instituto de Investigaciones Filosóficas-UnAM, México, 2008.

_- El búho y la serpiente. Ensayos sobre filosofía en México en el siglo xx, UNAM, México, 2007.

Instituto de Investigaciones Filosóficas, folleto, Instituto de Investigaciones Filosóficas-UnAM, México, 1984.

Salmerón, F., "El Instituto de Investigaciones Filosóficas", La palabra y el hombre, no. 26 (Xalapa, Ver.), abril-junio de 1978, pp. 3-19.

Recibido el 22 de diciembre de 2009; aceptado el 10 de marzo de 2010.

Diánoia, vol. LV, no. 64 (mayo 2010). 